\title{
Eicosanoid Production following One Bout of Exercise in Middle-Aged African American Pre- and Stage 1 Hypertensives
}

\author{
Sheara Williamson, ${ }^{1}$ Deepti Varma, ${ }^{2}$ Michael Brown, ${ }^{1,3}$ and Susan Jansen ${ }^{2}$ \\ ${ }^{1}$ Hypertension, Molecular, and Applied Physiology Laboratory, Department of Kinesiology, Temple University, \\ 1800 North Broad Street, Philadelphia, PA 19122, USA \\ ${ }^{2}$ Department of Chemistry, Temple University, Philadelphia, PA 19122, USA \\ ${ }^{3}$ Department of Kinesiology, The University of Maryland, College Park, MD 20742, USA
}

Correspondence should be addressed to Sheara Williamson, shearatoy@gmail.com

Received 23 August 2010; Revised 31 January 2011; Accepted 10 March 2011

Academic Editor: Iris Reuter

Copyright ( $) 2011$ Sheara Williamson et al. This is an open access article distributed under the Creative Commons Attribution License, which permits unrestricted use, distribution, and reproduction in any medium, provided the original work is properly cited.

Endothelial dysfunction and a sedentary lifestyle may be involved in the development of hypertension which is proliferative among middle-aged African Americans (AA). Signaling molecules derived from the oxidation of 20-carbon fatty acid molecules known as eicosanoids influence vascular tone. The relationship between aerobic fitness and eicosanoid formation following exercise in middle-aged African American hypertensives is unknown. Purpose. To determine the relationship between aerobic capacity and eicosanoid formation after a bout of moderate-intensity exercise in middle-aged AA hypertensives. Methods. Ten sedentary hypertensive AA underwent 50 min of aerobic exercise at $65 \% \mathrm{VO}_{2}$ max. Urine was collected for 24 hr on two occasions, prior to testing and immediately following the bout of exercise. Urinary metabolites of prostacyclin (6-keto $\mathrm{PGF}_{1 \alpha}$ ) and thromboxane (11$\mathrm{dTXB}_{2}$ ) were measured during the day and night periods by high-performance liquid chromatography (HPLC). Results. 6-keto $\mathrm{PGF}_{1 \alpha}$ levels significantly increased $(P=.04)$ following the bout of exercise compared to the control day. There was a significant relationship $(r=.49, P<.05)$ between 6-keto $\mathrm{PGF}_{1 \alpha}$ levels and $\mathrm{VO}_{2}$ max during the exercise day. Conclusion. Based on this preliminary study, there appears to be a relationship between aerobic capacity and exercise-induced 6-keto PGF $_{1 \alpha}$ production in middle-aged hypertensive AAs. AAs with lower $\mathrm{VO}_{2}$ max had lower 6-keto $\mathrm{PGF}_{1 \alpha}$ formation.

\section{Introduction}

Hypertension is a multifactorial disease that has high prevalence in African Americans [1, 2]. National surveys show that the majority of middle-aged, urban African Americans engage in little or no leisure-time physical activity [3]. This high prevalence of physical inactivity contributes to the disproportionate burden of obesity, hypertension, diabetes, and coronary heart disease in African Americans [3-5].

A number of important causal factors for hypertension have been identified. Research has implicated endothelial dysfunction as a factor involved in the pathogenesis of hypertension and is evident in the early stages of the development of coronary atherosclerosis [1, 6-9]. Hypertension is also more prevalent with advancing age. The prevalence of endothelial-impaired function disorders such as hypertension is disproportionately higher in the African American population in contrast to Caucasians $[1,2,10]$.

Eicosanoids are 20-carbon molecules derived from arachidonic acid, a polyunsaturated fatty acid. Cyclooxygenase 1 or 2 (COX-1 or COX-2) and cell-specific synthases convert free arachidonic acid to a biologically active compound. The biologically active eicosanoid binds to receptors on the target cell plasma membrane to cause a wide range of biologic effects including platelet aggregation, lymphocyte aggregation and proliferation, bronchoconstriction, and vasodilation or vasoconstriction. Stable metabolites of the eicosanoids can be measured in urine, plasma, or tissue and are thought to represent whole-body synthesis of eicosanoids $[11,12]$. 
TABle 1: Study timeline.

\begin{tabular}{|c|c|c|c|c|c|c|c|c|c|c|c|c|}
\hline \multirow{2}{*}{$\begin{array}{l}\text { Screening } \\
\text { Casual BP } \\
\text { Screening blood draw }\end{array}$} & \multicolumn{6}{|c|}{ Baseline } & \multicolumn{6}{|c|}{ Testing } \\
\hline & & & & & & $\begin{array}{l}24 \mathrm{hr} \\
\text { urine }\end{array}$ & $\begin{array}{l}\text { Diet logs } \\
\text { returned }\end{array}$ & & & & Exercise & $\begin{array}{l}24 \mathrm{hr} \\
\text { urine }\end{array}$ \\
\hline $\begin{array}{l}\text { Bruce maximal TM test } \\
\text { Modified GXT with gas }\end{array}$ & $\begin{array}{c}\text { Diet } \\
\log \end{array}$ & $\begin{array}{l}\text { Diet } \\
\log \end{array}$ & $\begin{array}{c}\text { Diet } \\
\log \end{array}$ & $\begin{array}{c}\text { Diet } \\
\log \end{array}$ & $\begin{array}{c}\text { Diet } \\
\log \end{array}$ & $\begin{array}{c}\text { Diet } \\
\log \end{array}$ & Diet & Diet & Diet & Diet & Diet & Diet \\
\hline analysis & Day 1 & Day 2 & Day 3 & Day 4 & Day 5 & Day 6 & Day 1 & Day 2 & Day 3 & Day 4 & Day 5 & Day 6 \\
\hline
\end{tabular}

Thromboxane $\left(\mathrm{TXA}_{2}\right)$, a vasoconstrictor and platelet aggregator, and prostacyclin $\left(\mathrm{PGI}_{2}\right)$, a vasodilator and antiplatelet aggregator, are the most well-characterized eicosanoids influencing vascular tone. $\mathrm{TXA}_{2}$, a very unstable compound produced by platelets, has thrombogenic properties and is cytotoxic. The stable metabolite of $\mathrm{TXA}_{2}$ is 11dehydro-thromboxane $\mathrm{B}_{2}\left(11-\mathrm{dTXB}_{2}\right)$. The stable metabolite of $\mathrm{PGI}_{2}$ is 6-keto $\mathrm{PGF}_{1 \alpha}$.

Acute exercise enhances the generation of reactive oxygen species (ROS) which can lead to the oxidation of lipids, proteins, and nucleic acids altering cellular function. The increase in ROS after acute exercise promotes an acute phase of local inflammation that characteristically induces the release of inflammatory cytokines. These cytokines stimulate the release of arachidonic acid and ultimately an increase in $\mathrm{PGI}_{2}$ production. Thus, the exercise-induced increase in $\mathrm{PGI}_{2}$ is a normal consequence following exercise $[13,14]$. A recent study by Zoladz reported an attenuated $\mathrm{PGI}_{2}$ release following exercise in coronary artery disease and hypertensive patients when compared to healthy controls [15]. There is contrasting evidence reported on exercise-induced $\mathrm{TXA}_{2}$ production. Some research indicates an increase in $\mathrm{TXA}_{2}$ following exercise when others have reported no change [1519].

There is little, if anything, known about the acute exercise-induced responses of $\mathrm{PGI}_{2}$ and $\mathrm{TXA}_{2}$ in middleaged African Americans. The purpose of the study was to assess the changes, if any, in $\mathrm{PGI}_{2}$ and $\mathrm{TXA}_{2}$ production following a single bout of aerobic exercise in middle-aged hypertensive African Americans.

\section{Protocol}

2.1. Participants. Participants were recruited from the Baltimore, MD and Washington, DC area. Ten volunteers (5 male, 5 female; $58 \pm 2.3$ yrs) completed the study. The participants were sedentary (regular aerobic exercise $\leq 2$ sessions/wk and $<20 \mathrm{~min} / \mathrm{session}$, sedentary occupation) African Americans who were categorized as having prehypertension (pre-HTN) or stage 1 hypertension (systolic and diastolic blood pressure (BP) $143 \pm 7 / 87 \pm 7 \mathrm{mmHg}$ ).

2.2. Screening. Subjects had a physical examination, routine fasting blood chemistries, and BP measured under standardized conditions. Inclusion criteria required participants to be pre- or stage 1 hypertensive according to the Seventh Report of the Joint National Committee on Prevention, Detection, Evaluation, and Treatment of High Blood Pres- sure (JNC 7) guidelines [2] having an average systolic BP of 120-139 mmHg (pre-HTN), 140-159 mmHg (stage 1), and a diastolic BP of $80-89 \mathrm{mmHg}$ (pre-HTN), or $90-99 \mathrm{mmHg}$ (stage 1). No participants were taking antihypertensive medications. BP level was determined by the average of three casual BP readings from three separate days according to the standards established by the JNC 7 guidelines. Blood samples were drawn in the morning following a 12-hour fast and sent to Quest Diagnostics for routine chemistries. In addition, blood lipids, serum creatinine, and glucose were also measured. Blood lipids were assessed to rule out hyperlipidemia; serum creatinine was measured to rule out renal dysfunction; fasting glucose was measured to rule out diabetes. Individuals with abnormal blood chemistries were excluded from further participation in the study. Each participant then underwent a physical examination by the study physician. Exclusion criteria included smoking, a body mass index (BMI) $>35$, alcohol intake of more than 3 drinks per day, diabetes (fasting glucose level $>126 \mathrm{mg} / \mathrm{dL}$ ), total cholesterol $>240 \mathrm{mg} / \mathrm{dL}$, and evidence of renal or cardiovascular disease.

The screening GXT was a maximal test to screen for signs and symptoms of coronary artery disease. During the test, the participants walked on a treadmill while their blood pressure, heart rate, and ECG response were monitored. The speed and/or degree of incline of the treadmill increased every 3 minutes until the participants could no longer continue or showed signs or symptoms of cardiovascular events. Participants having a negative screening graded exercise stress test (GXT) were excluded from further participation in the study. The study protocol was approved by the Institutional Review Board of the University of Maryland, College Park. Informed consent was obtained from each participant. A timeline of the protocol is provided in Table 1.

2.3. 24-Hour Urine Collection. Urine was collected for a 24hour period one week prior to the exercise session (Baseline). Samples were collected in five time periods (00:00-08:00, 08:00-12:00, 12:00-16:00, 16:00-20:00, and 20:00-0:00). Urine for each time period was collected in a separate container. All urine collection containers were kept on ice in a cooler for the entire 24-hour period. Subjects began urine collection after their first void in the morning and ended after their first void the following morning. Total urine volume was measured to the nearest $.5 \mathrm{~mL}$ and an aliquot of the pooled 24 hour urine was sent to Quest Diagnostics for determination of creatinine concentration. Creatinine is a breakdown product of creatine phosphate in muscle. In 
the absence of kidney dysfunction, creatinine clearance is relatively constant and can be used as a means to compare other excreted metabolites. Aliquots from each time period were frozen at $-80^{\circ} \mathrm{C}$ until analysis. A second 24-hour urine collection was repeated immediately following the exercise session.

2.4. Diet. Three days prior to beginning baseline testing, subjects were instructed to maintain their usual diets and complete a 6-day dietary log. Each subject was given their dietary information recorded during the baseline period and instructed to repeat the 6-day diet leading to the exercise day.

2.5. Graded Exercise Test to Measure Aerobic Capacity. A second GXT was completed a week prior to the exercise session. All subjects completed a maximal treadmill exercise test to derive a valid prescription for the acute exercise session. When oxygen consumption $\left(\mathrm{VO}_{2}\right)$ is added to a GXT, it is possible to measure $\mathrm{VO}_{2}$ max, an index of cardiovascular fitness. Participants began at $70 \%$ of the peak heart rate achieved on the subject's screening exercise test and the treadmill grade was increased 2\% every 2 minutes. Blood pressure, heart rate, and ECG were monitored during the test which was terminated when the subject could no longer continue. $\mathrm{VO}_{2}$ was measured continuously throughout this test using a mass spectrometer (Marquette), mixing chamber (Rayfield), turbine volume meter system (model VMM, Interface Associates), and customized validated metabolic software. Standard criteria were used to determine if $\mathrm{VO}_{2} \max$ had been achieved. Subjective criteria included the subject's rating of their perceived exertion and their physical inability to continue exercise. The objective criteria that were monitored were a plateau in rise in heart rate and a respiratory exchange ratio of greater than 1.15. The respiratory exchange ratio is determined by dividing the volume of $\mathrm{CO}_{2}$ expired per minute by the volume of $\mathrm{O}_{2}$ inspired per minute.

2.6. Acute Exercise Session. The goal of the exercise session was to accumulate 50 minutes of exercise. The exercise session began with a 10-minute warm-up consisting of walking and stretching exercises. The participants then walked on a treadmill for 30 minutes, followed by 5 minutes of rest, and then 20 additional minutes of treadmill walking or cycle ergometry for a total of 50 minutes of submaximal exercise. A heart rate monitor (Polar CIC, Inc.) was used to ensure that each subject's exercise heart rate corresponded to $65 \%$ of their aerobic capacity that was measured during the $\mathrm{VO}_{2} \max$ GXT. After completing the acute exercise session, participants began a 24 -hour urine collection period in the same manner as during the baseline collection.

\subsection{Measurement of 6-Keto $P G F_{1 \alpha}$ and 11-dTXB 2}

2.7.1. Chemicals and Materials. The prostaglandins (6-keto $\mathrm{PGF}_{1 \alpha}$ and 11-dTXB 2 ) were purchased from Biomol (Plymouth meeting, PA, USA). Creatinine was purchased from Sigma-Aldrich (St. Louis, MO, USA). Ortho Phosphoric acid, HPLC water, and acetonitrile were purchased from Fisher Scientific (Waltman, MA, USA).

2.7.2. Instrumentation. The Jasco HPLC system consisted of a Jasco pumps (PU-980), a Jasco UV-VIS detector (UV-975; Jasco Incorporated Easton, MD, USA), and a Rheodyne manual injector (Rheodyne LLC, Rohnert Park, CA, USA). Jasco-Borwin software (version 3.3.5) was used for data collection. The analysis was done on a Symmetry $\mathrm{C}_{18} 4.6 \times 250 \mathrm{~mm}$ column with $5 \mu \mathrm{m}$ particle size (Waters Corporation, Milford, MA, USA).

2.7.3. HPLC Method. Acetonitrile was used as the organic phase. Phosphoric acid solution $(\mathrm{pH}=4)$ was used as the aqueous phase as it gave much better chromatographic results than acetic acid solution. An acidic solution ( $\mathrm{pH}$ of 4) was necessary to maintain the eicosanoids in the neutral state. Creatinine, at $\mathrm{pH}=4$ which is below its $\mathrm{pKa}$ value (4.83) will be in the protonated form. Creatinine in this form will be retained for a very short period of time on a nonpolar stationary phase compared to the neutral form of 8-iso $\mathrm{PGF}_{2}$, a long-chain (C20) polyunsaturated fatty acid. The flow rate and ratio of the aqueous and organic phase were selected to obtain a method with a practical run time and which resulted in good separation of all the compounds. All the chromatograms showed a negative drop at around $3.0 \mathrm{~min}$. This is due to the change in the wavelength from $254 \mathrm{~nm}$ to $196 \mathrm{~nm}$. The HPLC method employed an isocratic elution of $17 \mathrm{mM}$ phosphoric acid (solvent A) and acetonitrile (solvent B) in the ratio of $65: 35$. The analytes were separated at ambient temperature with an injection volume of $100 \mu \mathrm{L}$ and using a flow rate of $1.3 \mathrm{~mL} / \mathrm{min}$. The run time for the method was $16.5 \mathrm{~min}$.

Urinary metabolites 6-keto $\mathrm{PGF}_{1 \alpha}$ and 11-dTXB 2 were dissolved in $1 \mathrm{~mL}$ methanol such that the stock mass concentration for all was $1 \mathrm{mg} / \mathrm{mL}$. $1000 \mathrm{mg}$ of creatinine was dissolved in $100 \mathrm{~mL}$ HPLC water to obtain a stock having concentration of $10 \mathrm{mg} / \mathrm{mL}$. Working standards for the analytes were prepared by serial dilution using $17 \mathrm{mM}$ phosphoric acid and acetonitrile in the ratio of $1: 1$ as the solvent. The solutions were stored at $-80^{\circ} \mathrm{C}$ when not in use. $75 \mu \mathrm{L}$ of the filtered urine samples was diluted to $500 \mu \mathrm{L}$ with a 1:1 mixture of $17 \mathrm{mM}$ phosphoric acid and acetonitrile before injecting into the HPLC system.

2.7.4. Linearity, Accuracy, and Precision and Recovery. The HPLC method was validated as per the FDA guidance for the industry: bioanalytical method validation [20]. The linear range for 6-keto $\mathrm{PGF}_{1 \alpha}$ and $11-\mathrm{dTXB}_{2}$, the metabolites of arachidonic acid, was established by injecting in triplicate standard solutions at mass concentrations ranging from their respective LOQ to $1000 \mathrm{ng}$. Both the compounds showed a good linear response with $R^{2}>0.999$ in the range. Accuracy was determined by analyzing the compounds at three different mass concentration levels. Percent accuracy for the prostanoids was between 90.3-101.5\%. Interassay and intra-assay precision were determined by injecting in triplicate. Intra-assay and interassay precision as indicated 
TABLE 2: Baseline demographic and clinical characteristics.

\begin{tabular}{lc}
\hline Male/female & $5 / 5$ \\
Age $($ years $)$ & $58 \pm 2.3$ \\
$\mathrm{BMI}\left(\mathrm{kg} / \mathrm{m}^{2}\right)$ & $30.5 \pm 1.1$ \\
$\mathrm{VO}_{2}(\mathrm{~mL} / \mathrm{kg} / \mathrm{min})$ & $22.6 \pm 1.2$ \\
$\mathrm{TC}(\mathrm{mg} / \mathrm{dL})$ & $214.8 \pm 9.2$ \\
$\mathrm{LDL}-\mathrm{C}(\mathrm{mg} / \mathrm{dL})$ & $131.8 \pm 10.1$ \\
$\mathrm{VLDL}-\mathrm{C}(\mathrm{mg} / \mathrm{dL})$ & $27.9 \pm 4.0$ \\
$\mathrm{HDL}-\mathrm{C}(\mathrm{mg} / \mathrm{dL})$ & $55.1 \pm 3.4$ \\
Casual Avg SBP $(\mathrm{mmHg})$ & $143 \pm 7$ \\
Casual Avg DBP $(\mathrm{mmHg})$ & $87 \pm 7$ \\
\hline
\end{tabular}

Values shown as mean \pm SEM.

$\mathrm{BMI}$ indicates body mass index; $\mathrm{VO}_{2}$, aerobic capacity; $\mathrm{TC}$, total cholesterol; LDL-C, low-density lipoprotein cholesterol; VLDL-C, very low-density lipoprotein cholesterol; HDL-C, high-density lipoprotein cholesterol; SBP, systolic blood pressure; DBP, diastolic blood pressure.

by the percent relative standard deviation (RSD) were $<10 \%$. The percent recovery for the prostanoids at the three concentration levels was within $95-108 \%$.

Instrument precision was determined by injecting a single mixture containing all the compounds six times and calculating the RSD values. RSD values were found to be less than $5 \%$ for all the analytes. The RSD values for all injections were $<10 \%$ for intra-assay precision, and all urine metabolites were normalized to ug of creatinine.

\section{Statistics}

For statistical analyses, we redefined the time periods to AM (08:00-16:00) and PM (16:00-00:00) because of insufficient data collected between 00:00-08:00. Descriptive statistics were performed for subject characteristics and are presented as mean \pm SEM in Table 2. For each urinary metabolite (6keto $\mathrm{PGF}_{1 \alpha}$ and $11-\mathrm{dTXB}_{2}$ ), a repeated measures ANOVA comparing groups at the two time periods; before and after acute exercise bout. Repeated measures ANCOVA was used to covary for age, BMI, and aerobic fitness. Separate simple linear regression analyses were performed with $\mathrm{VO}_{2} \max$ as the independent variable and each of the urinary metabolites as the dependent variables. Values are presented as mean \pm SEM. A value of $P \leq .05$ was considered statistically significant. Statistical analysis was performed using STATVIEW (SAS Institute, Cary, NC).

\section{Results}

Subject characteristics are shown in Table 2. Ten African American men and women ( 5 male, 5 female), age $58 \pm$ 2.3 years, participated in the study. $\mathrm{VO}_{2}$ max determined from the GXT ranged from $17.4-29.3 \mathrm{~mL} / \mathrm{kg} / \mathrm{min}$ (mean $22.6 \pm 1.2 \mathrm{~mL} / \mathrm{kg} / \mathrm{min}$ ), which would classify all participants as sedentary. The average LDL-C for the participants was $131.8 \pm 10.1$, which is borderline high according to the American Heart Association guidelines.
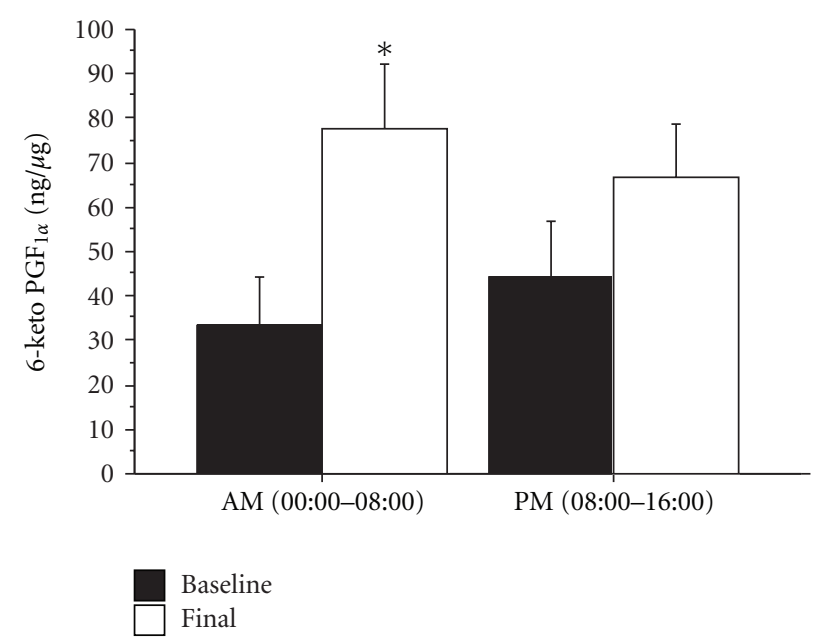

FIgure 1: Urinary 6-keto $\mathrm{PGF}_{1 \alpha}$ levels increased from $33.5 \pm$ $11 \mathrm{ng} / \mathrm{ug}$ to $77.8 \pm 14.1 \mathrm{ng} / \mathrm{ug}$ during the AM period after the bout of exercise when compared to baseline. Levels returned to near baseline during the PM collection following the exercise bout, ${ }^{*} P<.05$.

The urinary metabolites were examined at two time periods: 08:00-16:00 (AM) and 16:00-00:00 (PM) by ANOVA. Baseline levels of 6-keto $\mathrm{PGF}_{1 \alpha}$ and $11-\mathrm{dTXB}_{2}$ were $33.5 \pm$ $10.9 \mathrm{ng} / \mathrm{ug}$ and $50.8 \pm 20.4 \mathrm{ng} / \mathrm{ug}$ in the AM, respectively. 6keto $\mathrm{PGF}_{1 \alpha}$ levels increased by more that twofold from $33.5 \pm$ $10.9 \mathrm{ng} / \mathrm{ug}$ at baseline to $77.8 \pm 14.1 \mathrm{ng} / \mathrm{ug}(P<.05$; Figure 1$)$ during the AM collection period after the acute exercise session. ANCOVA using $\mathrm{VO}_{2} \max$ as the only covariate, followed by Fisher's PLSD, improved the effect of the acute exercise bout $(P=.03)$. Based on regression analysis, there was a significant relationship $(P=.04)$ between 6keto $\mathrm{PGF}_{1 \alpha}$ levels and $\mathrm{VO}_{2}$ max during the $\mathrm{AM}$ collection period following exercise (Figure 2). Regression analysis also identified $\mathrm{VO}_{2}$ max as a significant predictor of 6-keto $\mathrm{PGF}_{1 \alpha}$ following the exercise bout.

Correlational analysis conducted using the baseline values revealed a significant positive relationship $(r=.97, P=$ .04 AM collection; $r=.99, P=.01 \mathrm{PM}$ collection) between LDL-C and 11- $\mathrm{dTXB}_{2}$. This relationship was not observed between LDL-C and 6-keto PGF $_{1 \alpha}$. Analysis also revealed a significant negative correlation between 6-keto $\mathrm{PGF}_{1 \alpha}$ levels and age $(r=-.92, P=.003)$.

The urinary $11-\mathrm{dTXB}_{2}$ concentrations were decreased at both collection times; $51 \% \mathrm{AM}$ and 35\% PM relative to baseline levels; however, this trend, though reproducible and consistent throughout the study, did not meet the test of significance as defined by $P \leq .05$ following the acute exercise session.

\section{Discussion}

Increases in vascular shear stress and mobilization and activation of cytokines and immune cells occur as a result of exercise. This leads to arachidonic acid liberation from the plasma membrane. COX-1 or COX-2 and cell-specific 


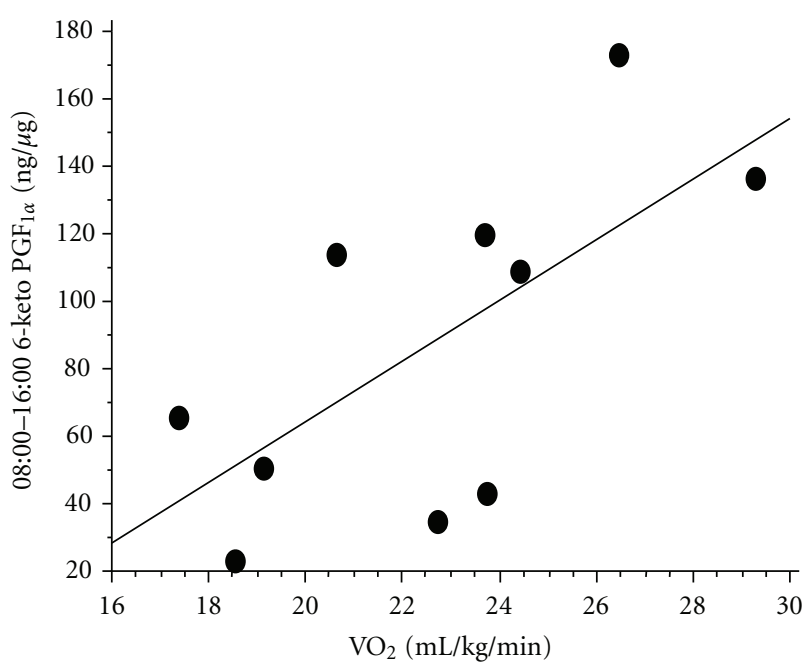

Figure 2: 6-keto $\mathrm{PGF}_{1 \alpha}$ measured in urine collected in the AM following a moderate intensity exercise bout was found to significantly correlate with $\mathrm{VO}_{2}$ max in sedentary African American pre- and stage 1 hypertensives $(r=.67, P<.05)$.

synthases convert the free arachidonic acid to a biologically active compound with cytoprotective properties.

Platelet activation increases during exercise. It has been suggested that metabolic activity in the arachidonic acid cascade may be increased equally at various exercise intensity levels, but that the synthesis of $\mathrm{PGI}_{2}$ and $\mathrm{TXA}_{2}$ may be more heavily influenced by the exercise intensity level [16]. Alternatively, the conversion of arachidonic acid to eicosanoids other than $\mathrm{PGI}_{2}$ and $\mathrm{TXA}_{2}$ may be affected by exercise, which may be responsible for the observed decrease in $11-\mathrm{dTXB}_{2}$ following the acute exercise bout. The increase in $\mathrm{PGI}_{2}$ generation could be compensating for the prothrombotic environment induced by exercise. Prostacyclin production is initiated by an influx of calcium into the cytoplasm resulting from the emptying of intracellular stores, which occurs only in the initial minutes of cellular activation [21]. This could explain why the increase in the excretion of 6-keto $\mathrm{PGF}_{1 \alpha}$ occurred in the morning following the exercise bout and not later in the day.

Rodrigo et al. reported that blood antioxidant activity was lower in hypertensives when compared to normotensive controls [22]. Acute exercise enhances the generation of ROS, which can lead to the oxidation of lipids, proteins and, nucleic acids leading to altered cellular function. ROS increases the expression of antioxidant enzymes, but this is attenuated in hypertensives $[23,24]$. It has been documented that, in a hypertensive population, plasma levels of 6-keto $\mathrm{PGF}_{1 \alpha}$ were significantly lower than those of healthy controls [21]. In the current study, individuals who were more aerobically fit (assessed by $\mathrm{VO}_{2} \max$ ) produced higher concentrations of urinary 6-keto $\mathrm{PGF}_{1 \alpha}$ following an acute bout of exercise. This may suggest that there is greater antioxidant activity in those individuals who are more aerobically fit than those who are less aerobically fit.
Laustiola et al. and Carter et al. observed that plasma levels of 6-keto $\mathrm{PGF}_{1 \alpha}$ increased following a low-intensity $\left(30-50 \% \mathrm{VO}_{2} \max \right)$ bout of exercise, which suggests that exercise at lower intensities may stimulate a greater production of 6-keto $\mathrm{PGF}_{1 \alpha}$ [16]. This trend was seen in the present study population with a 1.5 -fold to 2 -fold increase in 6-keto $\mathrm{PGF}_{1 \alpha}$. Todd et al. showed that 6-keto $\mathrm{PGF}_{1 \alpha}$ levels decreased incrementally as exercise intensity increased to near maximal levels [16]. In the present study, moderate intensity aerobic exercise increased urinary levels of 6-keto $\mathrm{PGF}_{1 \alpha}$ following exercise in the AM urine sample. This is consistent with findings by Okahara et al. that have documented an increase in 6-keto $\mathrm{PGF}_{1 \alpha}$ production as a result of increased vascular shear stress and cytokine release [25]. The 6-keto $\mathrm{PGF}_{1 \alpha}$ levels during the PM sample were not different than the baseline day.

Tokunga et al. demonstrated an age-related decline in $\mathrm{PGI}_{2}$ synthesis which is consistent with our findings. Reduced $\mathrm{PGI}_{2}$ production, as a result of aging or selective COX-2 inhibition, has been proposed as a mechanism involved in the atherogenic process, myocardial infarctions, and stroke [26, 27]. Nicholson et al. reported that forearm vasodilation responses to $\mathrm{PGI}_{2}$ were significantly impaired in an older group when compared to a younger group matched for BMI and sex. They further suggested agerelated differences in $\mathrm{PGI}_{2}$-mediated vasodilation are likely attributed to a reduced contribution of the endotheliumderived relaxing factor, nitric oxide ( $\mathrm{NO}$ ) [27]. In a race comparison study, healthy African Americans demonstrated blunted NO-mediated vasodilation when compared to a group of healthy Caucasians supporting evidence of racerelated defects in endothelial function [10].

The highly reactive oxygen radical, superoxide anion $\left(\mathrm{O}_{2}{ }^{-}\right)$has a high affinity for $\mathrm{NO}$, which increases the likelihood of the inactivation of $\mathrm{NO}$ and the formation of peroxynitrite $\left(\mathrm{ONOO}^{-}\right)$, a potent oxidant $[28,29]$. Kalinowksi et al. reported racial differences in the steadystate $\mathrm{NO} / \mathrm{O}_{2}{ }^{-} / \mathrm{ONOO}^{-}$balance in endothelial cells from African Americans. Basal levels are reportedly closer to the redox states characteristic for endothelium-impaired function disorders [1]. In the current study, LDL-C was highly correlated with the urinary metabolite $11-\mathrm{dTXB}_{2}$ at baseline. LDL-C has been reported to increase the generation of $\mathrm{O}_{2}{ }^{-}$, along with NO. Weisser et al. showed that LDL$\mathrm{C}$ increases thromboxane synthesis in a dose-dependent manner [30]. Kuklinska et al. reported a significant negative correlation between LDL-C and $\mathrm{PGI}_{2}$ but we did not observe such a finding [6].

Decreases of 11- $\mathrm{dTXB}_{2}$ following the exercise session could be due to arachidonic acid being used as a precursor for prostacyclin to compensate for the prothrombotic state. $\mathrm{TXA}_{2}$ synthase may be at the same expression level, but competing PGI synthase may be in higher concentrations. Todd et al. suggested that exercise intensities below $70 \%$ of $\mathrm{VO}_{2}$ max may not be sufficient to stimulate significant alterations in $\mathrm{TXA}_{2}$ activity [16]. There has been some conflicting evidence in regards to how exercise influences $\mathrm{TXA}_{2}$ concentrations following exercise. Aerobically trained individuals seem to have an enhanced antioxidant system 
$[29,31]$, which could explain the lack of significant alterations in $\mathrm{TXA}_{2}$ activity at the low exercise intensity.

Increased risk and incidence of disease are associated with low aerobic capacity [5]. In the present study, there was a relationship between aerobic capacity as assessed by $\mathrm{VO}_{2} \mathrm{max}$ and exercise-induced $\mathrm{PGI}_{2}$ production in preand stage 1 middle-aged hypertensive African Americans. African American subjects with lower $\mathrm{VO}_{2}$ max had lower $\mathrm{PGI}_{2}$ formation. Impaired $\mathrm{PGI}_{2}$ production in response to exercise may be suggestive of endothelial dysfunction. When racial comparisons are made, the endothelium of African Americans is closer to the state characteristic for endothelium-impaired functional disorders than Caucasians [1]. This may explain, in part, the predisposition of African Americans to complications associated with cardiovascular disease.

The middle-aged participants were carefully screened to provide us with a homogenous population of healthy participants. The strict inclusion criteria lead to the small sample size which is a limiting factor of this study. The lack of significance found for the urinary metabolite $11-\mathrm{dTXB}_{2}$ following the acute exercise bout could be due to the small sample size and/or the intensity level of the exercise session.

\section{Conclusion}

William Aird suggests that to develop an understanding of the endothelium in health and disease, one would have to look back at the early ancestral environment where the endothelium evolved to a state of maximal fitness [32]. He further comments that the endothelium is not adapted to withstand the rigors of high fat diet, epidemics associated with high-density populations, sedentary lifestyle, or old age.

The present study examined the most well-characterized eicosanoids affecting endothelial function in a population of sedentary, middle-aged pre- and stage 1 hypertensive African Americans who reside in an urban area. Our preliminary study showed that those with a lower aerobic capacity had a diminished capacity to produce $\mathrm{PGI}_{2}$, the cardioprotective eicosanoid produced by the vascular endothelium, after exercise. Future studies should examine the effects of longterm aerobic exercise training and diet change (in order to mimic ancestral eating habits) on endothelial function in African American hypertensives.

\section{References}

[1] L. Kalinowski, I. T. Dobrucki, and T. Malinski, "Race-specific differences in endothelial function: predisposition of African Americans to vascular diseases," Circulation, vol. 109, no. 21, pp. 2511-2517, 2004.

[2] A. V. Chobanian, G. L. Bakris, H. R. Black et al., "Seventh report of the joint national committee on prevention, detection, evaluation, and treatment of high blood pressure," Hypertension, vol. 42, no. 6, pp. 1206-1252, 2003.

[3] C. J. Crespo, E. Smit, R. E. Andersen, O. Carter-Pokras, and B. E. Ainsworth, "Race/ethnicity, social class and their relation to physical inactivity during leisure time: results from the Third
National Health and Nutrition Examination Survey, 19881994," American Journal of Preventive Medicine, vol. 18, no. 1, pp. 46-53, 2000.

[4] W. L. Haskell, I. M. Lee, R. R. Pate et al., "Physical activity and public health: updated recommendation for adults from the American College of Sports Medicine and the American Heart Association," Medicine and Science in Sports and Exercise, vol. 39, no. 8, pp. 1423-1434, 2007.

[5] B. A. Murray, C. J. Brahler, J. Baer, and J. Marotta, "Correlations between activity and blood pressure in African American womenand girls," Journal of Exercise Physiology Online, vol. 6, no. 3, pp. 38-44, 2003.

[6] A. M. Kuklinska, B. Mroczko, W. J. Musial et al., "Diagnostic biomarkers of essential arterial hypertension: the value of prostacyclin, nitric oxide, oxidized-LDL, and peroxide measurements," International Heart Journal, vol. 50, no. 3, pp. 341351, 2009.

[7] P. Minuz, C. Fava, and A. Lechi, "Lipid peroxidation, isoprostanes and vascular damage," Pharmacological Reports, vol. 58, pp. S57-S68, 2006.

[8] C. Chrysohoou, D. B. Panagiotakos, C. Pitsavos et al., "The association between pre-hypertension status and oxidative stress markers related to atherosclerotic disease: the ATTICA study," Atherosclerosis, vol. 192, no. 1, pp. 169-176, 2007.

[9] C. M. Stein, C. C. Lang, R. Nelson, M. Brown, and A. J. J. Wood, "Vasodilation in black Americans: attenuated nitric oxide-mediated responses," Clinical Pharmacology and Therapeutics, vol. 62, no. 4, pp. 436-443, 1997.

[10] C. Cardillo, C. M. Kilcoyne, R. O. Cannon, and J. A. Panza, "Attenuation of cyclic nucleotide-mediated smooth muscle relaxation in blacks as a cause of racial differences in vasodilator function," Circulation, vol. 99, no. 1, pp. 90-95, 1999.

[11] P. M. Vanhoutte, "COX-1 and vascular disease," Clinical Pharmacology and Therapeutics, vol. 86, no. 2, pp. 212-215, 2009.

[12] M. P. Reilly, J. A. Lawson, and G. A. Fitzgerald, "Eicosanoids and isoeicosanoids: indices of cellular function and oxidant stress," Journal of Nutrition, vol. 128, no. 2, pp. s434-s438, 1998.

[13] R. H. Boger, S. M. Bode-Boger, E. P. Schroder, D. Tsikas, and J. C. Frolich, "Increased prostacyclin production during exercise in untrained and trained men: effect of low-dose aspirin," Journal of Applied Physiology, vol. 78, no. 5, pp. 1832-1838, 1995.

[14] D. J. Fitzgerald, F. Catella, L. Roy, and G. A. FitzGerald, "Marked platelet activation in vivo after intravenous streptokinase in patients with acute myocardial infarction," Circulation, vol. 77, no. 1, pp. 142-150, 1988.

[15] J. A. Zoladz, J. Majerczak, K. Duda, and S. Chłopicki, "Exercise-induced prostacyclin release positively correlates with Vo in young healthy men," Physiological Research, vol. 58, no. 2, pp. 229-238, 2009.

[16] M. K. Todd, A. H. Goldfarb, and B. T. Boyer, "Effect of exercise intensity on 6-keto-PGF $(1 \alpha), \mathrm{TXB}$, and 6-keto-PGF( $1 \alpha) / \mathrm{TXB}$ ratios," Thrombosis Research, vol. 65, no. 4-5, pp. 487-493, 1992.

[17] K. Petidis, S. Douma, M. Doumas, I. Basagiannis, K. Vogiatzis, and C. Zamboulis, "The interaction of vasoactive substances during exercise modulates platelet aggregation in hypertension and coronary artery disease," BMC Cardiovascular Disorders, vol. 8, article 11, 2008. 
[18] A. S. Kestin, P. A. Ellis, M. R. Barnard, A. Errichetti, B. A. Rosner, and A. D. Michelson, "Effect of strenuous exercise on platelet activation state and reactivity," Circulation, vol. 88, no. 4 I, pp. 1502-1511, 1993.

[19] L. Nailin, N. H. Wallén, and P. Hjemdahl, "Evidence for prothrombotic effects of exercise and limited protection by aspirin," Circulation, vol. 100, no. 13, pp. 1374-1379, 1999.

[20] US Food and Drug Administration, Guidance for Industry: Bioanalytical Method Validation, US Department of Health and Human Services, Food and Drug Administration, Center for Drug Evaluation and Research, 2001.

[21] J. Mitchell, F. Ali, L. Bailey, L. Moreno, and L. Harrrington, "Role of nitric oxide and prostacyclin as vasoactive hormones released by the endothelium," Experimental Physiology, vol. 93, no. 1, pp. 141-147, 2007.

[22] R. Rodrigo, H. Prat, W. Passalacqua, J. Araya, C. Guichard, and J. P. Bächler, "Relationship between oxidative stress and essential hypertension," Hypertension Research, vol. 30, no. 12, pp. 1159-1167, 2007.

[23] B. Singh, S. K. Awasthi, M. Chandra, and K. Shanker, "Antioxidant enzymes and lipid peroxidation of human blood platelets in essential hypertension," Asia Pacific Journal of Pharmacology, vol. 15, no. 3, pp. 57-60, 2001.

[24] S. Wassmann, K. Wassmann, and G. Nickenig, "Modulation of oxidant and antioxidant enzyme expression and function in vascular cells," Hypertension, vol. 44, no. 4, pp. 381-386, 2004.

[25] K. Okahara, B. Sun, and J. I. Kambayashi, "Upregulation of prostacyclin synthesis-related gene expression by shear stress in vascular endothelial cells," Arteriosclerosis, Thrombosis, and Vascular Biology, vol. 18, no. 12, pp. 1922-1926, 1998.

[26] O. Tokunga, T. Yamada, J. L. Fan, and T. Watanabe, "Agerelated decline in prostacyclin synthesis by human aortic endothelial cells. Qualitative and quantitative anaylysis," American Journal of Pathology, vol. 138, no. 4, pp. 941-949, 1991.

[27] W. T. Nicholson, B. Vaa, C. Hesse, J. H. Eisenach, and M. J. Joyner, "Aging Is Associated with reduced prostacyclinmediated dilation in the human forearm," Hypertension, vol. 53, no. 6, pp. 973-978, 2009.

[28] R. J. Gryglewski, R. M. J. Palmer, and S. Moncada, "Superoxide anion is involved in the breakdown of endothelium-derived vascular relaxing factor," Nature, vol. 320, no. 6061, pp. 454456, 1986.

[29] L. Santangelo, L. Cigliano, A. Montefusco et al., "Evaluation of the antioxidant response in the plasma of healthy or hypertensive subjects after short-term exercise," Journal of Human Hypertension, vol. 17, no. 11, pp. 791-798, 2003.

[30] B. Weisser, R. Locher, J. De Graaf, R. Moser, A. Sachinidis, and W. Vetter, "Low density lipoprotein subfractions increase thromboxane formation in endothelial cells," Biochemical and Biophysical Research Communications, vol. 192, no. 3, pp. 1245-1250, 1993.

[31] N. Kostic, Z. Caparevic, D. Marina et al., "Impact of acute exercise on antioxidant enzymes activity and lipid status in blood of patients with hypertension," Military-Medical and Pharmaceutical Review, vol. 66, no. 9, pp. 695-699, 2009.

[32] W. C. Aird, "Spatial and temporal dynamics of the endothelium," Journal of Thrombosis and Haemostasis, vol. 3, no. 7, pp. 1392-1406, 2005. 


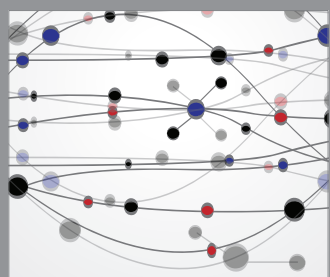

The Scientific World Journal
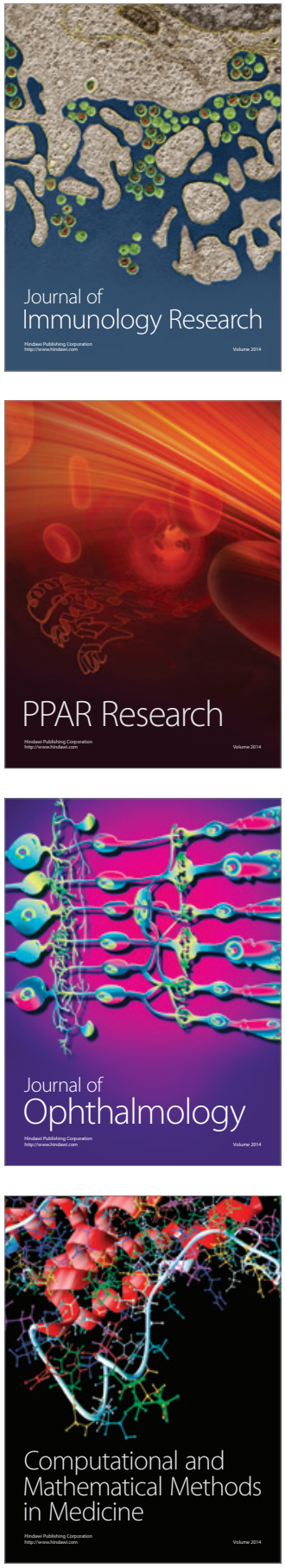

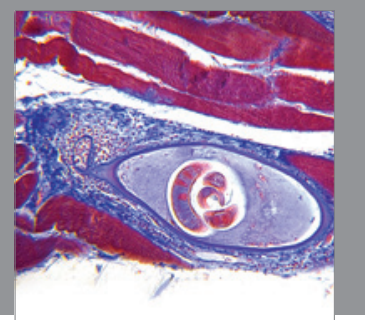

Gastroenterology

Research and Practice
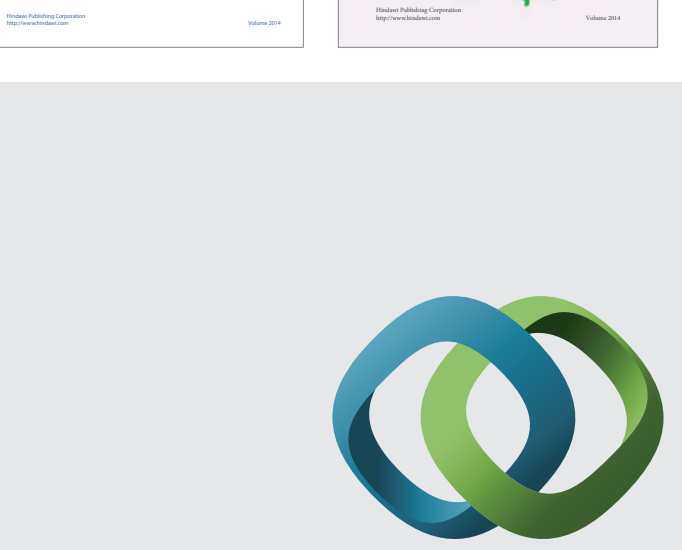

\section{Hindawi}

Submit your manuscripts at

http://www.hindawi.com
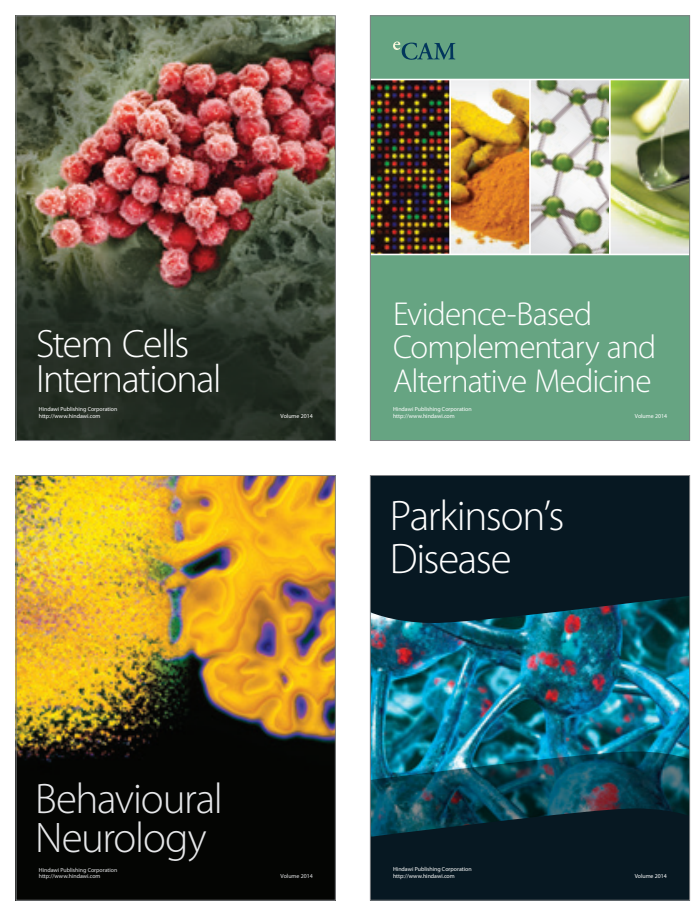

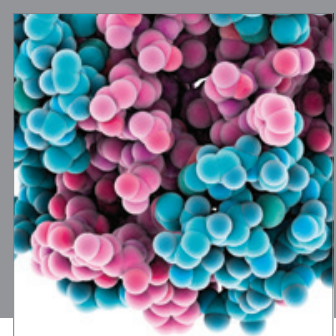

Journal of
Diabetes Research

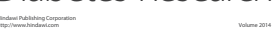

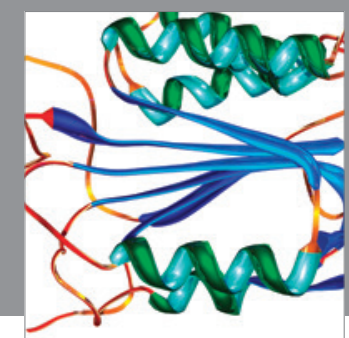

Disease Markers
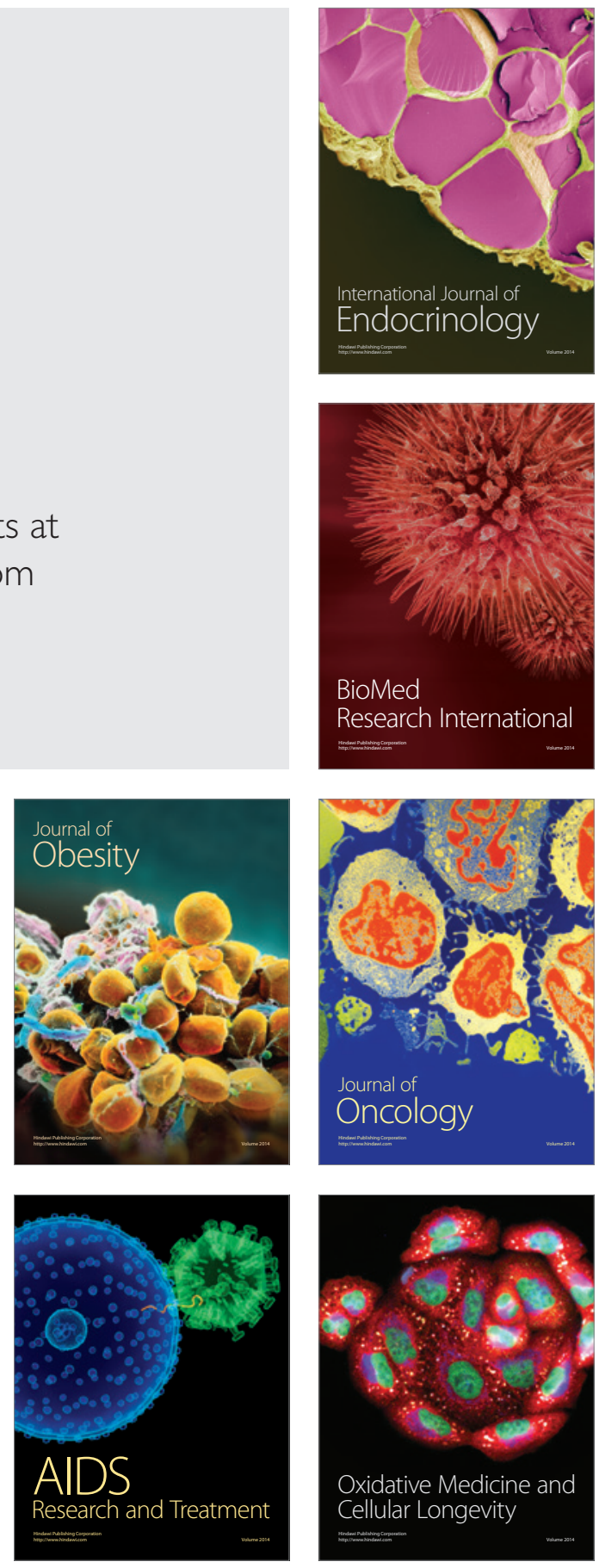